ФАРМАКОЛОГИЯ, КЛИНИЧЕСКАЯ ФАРМАКОЛОГИЯ PHARMACOLOGY

\title{
Correction of hypertensive retinal changes in rats with Semax
}

\author{
Sergey S. Lugovskoy ${ }^{1}{ }^{\circledR}$, Sofia S. Chernyaeva ${ }^{1}{ }^{\circledR}$, Anna A. Peresypkina ${ }^{1}{ }^{\mathbb{D}}$, \\ Anna S. Pobeda ${ }^{1}{ }^{\circledR}$, Nikolai V. Solovev ${ }^{2}{ }^{\mathbb{D}}$, Kristina V. Shchurovskaya ${ }^{1}{ }^{\mathbb{D}}$, \\ Igor N. Iezhitsa ${ }^{3}$ \\ ${ }^{1}$ Belgorod State National Research University, \\ 85 Pobedy St., Belgorod, 308015, Russia \\ ${ }^{2}$ Ophthalmological Clinical Hospital - Ophthalmological Center, \\ 42a Sadovaya St., Kursk, 305004, Russia \\ ${ }^{3}$ International Medical University, \\ 126 Jln Jalil Perkasa 19, Bukit Jalil, 57000, Malaysia \\ Corresponding author: Anna A. Peresypkina (peresypkina_a@bsu.edu.ru)
}

\begin{abstract}
Background: Currently, there are no drugs for the specific treatment of hypertensive retinal changes. The main therapy is for the treatment of a systemic disease - hypertensive disease. Therefore, the search for ways of specific pharmacological correction of hypertensive retinal changes is of great interest. The aim of the study: To evaluate the correction possibility of retinal injuries with Semax in a rat model of hypertensive neuroretinopathy. Materials and methods: The model was performed by injection of N-nitro-L-arginine methyl ester (L-NAME) at a dose of $1.25 \mathrm{mg} / 100$ $\mathrm{g}$ of rat mass within 28 days and a single increase in intraocular pressure (IOP) to $110 \mathrm{mmHg}$ for $5 \mathrm{~min}$. The retinoprotective effect of Semax at a dose of $7.2 \mu \mathrm{g} / 100 \mathrm{~g}$ of rat mass, in comparison with Picamilon at a dose of $3 \mathrm{mg} / 100 \mathrm{~g}$ of rat mass, was estimated by laser Doppler flowmetry (LDF) and electroretinography (ERG). Results: The use of Semax led to an increase in retinal perfusion by $62.7 \%, \mathrm{p}<0.05$, in comparison with the group with the model, and by $9.9 \%, \mathrm{p}<0.05$, in comparison with Picamilon; an increase in the b/a coefficient by $31.4 \%$ in comparison with the group with the model, $\mathrm{p}<0.05$, and by $14.6 \%$, $\mathrm{p}<0.05$ in comparison with Picamilon. Conclusion: The neuroretinoprotective effect of Semax in correction of hypertensive retinal changes in rats may be due to the presence of neuroprotective, neurometabolic, antioxidant and endothelioprotective effects in Semax. Thus, Semax can be a promising agent in hypertensive neuroretinopathy treatment.
\end{abstract}

Keywords: Semax; hypertensive neuroretinopathy; rats; laser doppler flowmetry; electroretinography 
For citation: Lugovskoy SS, Chernyaeva SS, Peresypkina AA, et al. Correction of hypertensive retinal changes in rats with Semax. Research Results in Biomedicine. 2021;7(3):272-280. DOI: 10.18413/2658-6533-2021-7-3-0-6

Introduction. With long-term, advanced hypertensive disease, the target organs (retina, kidneys, brain) are affected. Hypertension can affect the eyes in several ways, including the development of retinopathy and optic neuropathy. Hypertension is a risk factor for other eye diseases, including occlusion of the central retinal artery (CRA) and its branches, macroaneurysms of the retinal arteries and others $[1,2]$.

Published data indicate a $3-14 \%$ prevalence of hypertensive retinopathy in patients over 40 years of age. The pathogenetic link of hypertensive retinopathy is retinal ischemia, which can lead to the optic nerve atrophy [3, $4,5]$. In $63 \%$ of patients with hypertension, there are manifestations of hypertensive angiopathy. Vascular endothelium is attributed to the most early damaged target organ in hypertension, as well as to the cause of increased blood pressure $[6,7]$.

Special interest is paid to the development of short-chain peptide drugs for the cytoprotection $[8,9,10,11,12]$, in particular, neuroprotection [13, 14]. One of the actively studied classes of peptide regulators are melanocortins, which accelerate regeneration in the neuromuscular system, have a protective effect on damage to the central nervous system. Melanocortins have hormonal activity, positive effect on the development of the nervous system, etc. This class of peptides includes an analog of adrenocorticotropic hormone $(\mathrm{ACTH})_{(4-10)}$ with prolonged action Semax. To date, Semax is the only widely used in clinic neurotropic drug developed on the basis of melanocortins. Semax has no hormonal activity and retains a significant part of the spectrum of neurotropic effects of natural melanocortins. The heptapeptide Semax is a synthetic analogue of $\mathrm{ACTH}_{(4-10)}$ which exerts marked nootropic and neuroprotective activities [15], protects effectively the brain against ischemic stroke [14]. Semax promotes the survival of neurons during glutamate excitotoxicity [16], protects against the optic nerve atrophy and optic neuritis of inflammatory or toxic-allergic etiology [17].

At present, the spectrum of physiological and pharmacological activity of Semax is actively being studied, because many aspects of the therapeutic effects of this drug remain unknown. Based on literature data, tripeptide Pro-Gly-Pro (PGP) was predominant in a mixture of Semax derivatives in rat blood plasma and brain tissues just $1 \mathrm{~h}$ after intraperitoneal administration of Semax [18]. Independent effects of PGP were revealed recently, including an effect on cell culture survival in oxidative stress [19]. The effect of Semax and PGP previously was shown on the expression of genes that encode neurotrophic factors and their receptors in a model of brain ischemia in rats [20]. However, despite the advances described above, the molecular mechanisms underlying the Semax neuroprotective action and the degree of PGP participation in them remain obscure [15].

In cerebral ischemia, Semax showed neuroprotective, neurometabolic and antioxidant effects, and also promotes the synthesis of BDNF and NGF in the brain [13]. It was shown that Semax and PGP increased proliferation of the neuroglia, endothelium, and progenitor cells in the subventricular zone. Semax influences the genes expression associated with the vasodilation of arteries. It was shown that capillary bore dilation was observed as early as $15 \mathrm{~min}$ after the administration of Semax [20].

Under transient middle cerebral artery occlusion (tMCAO) conditions, it was found that Semax initiated mRNA expression that counteracted ischaemia-reperfusion (IR). In particular, Semax suppressed inflammatory and activated neurotransmitter genes, whereas the genetic response initiated by IR activates inflammatory and suppresses neurotransmitter genes. It was revealed that significant compensation effects of Semax peptide on inflammatory and neurotransmitter genetic responses after tMCAO, which may account for 
the neuroprotective action of Semax under IR conditions. Thus, an important feature of Semax is the normalization of mRNA expression patterns that are disturbed during ischaemia [21].

An important feature of Semax is the speed of the onset of the therapeutic effect, the absence of drug dependence and withdrawal syndrome. After intranasal administration, Semax penetrates the blood-brain barrier within a few minutes, and with a single administration, the therapeutic effect lasts up to 24 hours. The prolonged action of Semax is due to its sequential transformation, while most of the properties of the drug are preserved in its fragments EHFPGP and HFPGP. These fragments are quite stable and independently modulate cholinergic neurotransmission and nitric oxide synthesis [13].

Intranasal administration of Semax over the 7-day treatment course resulted in a $25 \%$ decrease of infarct volume in the prefrontal cortex and cognitive function recovery over the long term [22]. Recently, it was shown that Semax activates and induces PGC- $1 \alpha$ in the penumbral neurons in a model of focal ischemia and exert neuroprotective effects through these mechanisms. The target molecule - the PGC- $1 \alpha$ transcriptional coactivator is known for its pleiotropic potentiating effect on neuron viability and functionality. This study was performed in a model of photochemically induced thrombosis of prefrontal cortex blood vessels, mimicking the pathogenesis of acute ischemic stroke. Indeed, on the third day after photochemical-induced thrombosis, signs of degenerative changes in the microcirculatory bed were detected, such as multiple hemorrhages, pronounced vasodilation, and erythrocyte stasis. Secondary poststroke perfusion disturbances led to a significant progression of the penumbra, while the administration of Semax limited the disturbances of peri-infarction microcirculation observed after photochemical-induced thrombosis [23].

The intramuscular injection of Semax at a dose of $200 \mu \mathrm{g} / \mathrm{kg}$ for 10 days in animals with diabetes did not significantly influence the content of circulating endothelial cells and stable metabolites of NO, but the concentration of von Willebrand factor and endothelin1 was significantly reduced (by 16.8 and $15.4 \%$, respectively, $\mathrm{p}<0.01$ ) as compared to the control [24].

In addition, it was shown that the administration of Semax had antioxidant action and caused the increase in the antioxidant enzymes activity in a model of diabetes mellitus. Under the influence of Semax, the content of ceruloplasmin was lower. The administration of Semax and Sulodexid had antioxidant action, similar to Semax injection only. The decrease in the content of malondialdehyde was $17.8 \%(p<0.01)$, and acylhydroperoxides - by $28.4 \%$ ( $p<0.01)$. The drug had a stimulating action on the activity of superoxide dismutase (SOD) (by 32.7\% compared to the control, $\mathrm{p}<0.01$ ) and catalase - by $23.6 \%$ $(p>0.05)$. The received results show the antioxidant action of Semax in diabetes mellitus and confirm the prospect of their use in the endothelial dysfunction correction as a separate drug or in the combination with some other endothelioprotectors [25].

Studying the new perspective ways of neuroprotection in retinal injuries, in particular, developing in hypertension, is of great interest [26]. Therefore, an important task is to find specific and effective agents for treatment of hypertensive neuroretinopathy. To study the new pharmacological properties of drugs, it is necessary to conduct further studies in vivo [27, 28, 29, 30] on the adequate experimental pathology models [31].

Thus, it is perspective to study the possibility of pharmacological correction of hypertensive retinal changes with Semax in laboratory rats.

The aim of this research is to evaluate the correction possibility of retinal injuries with Semax in a rat model of hypertensive neuroretinopathy.

\section{Materials and Methods}

Animals. The experiments were conducted on 40 Wistar rats of average weight $250 \mathrm{~g}$. For the study, the healthy animals were taken, having passed the quarantine. Ethical principles of conducting experiments on laboratory rats were observed in accordance 
with the European Convention for the Protection of Vertebrate Animals Used for Experimental and Other Scientific Purposes, CETS No. 123. Manipulations on animals were performed under general anaesthesia with intraperitoneal (i.p.) administration of chloral hydrate solution at a dose of $30 \mathrm{mg} / 100 \mathrm{~g}$ of rat mass.

Design of the Experiment. The experiment included the following groups: $(\mathrm{n}=10)$

1) a control (with i.p. saline for 28 days)

2) a group with simulated hypertensive neuroretinopathy (HNRP) $(\mathrm{n}=10)$;

3) a group with Semax at a dose of 7.2 $\mu \mathrm{g} / 100 \mathrm{~g}$ in the model of HNRP $(\mathrm{n}=10)$;

4) a group with Picamilon at a dose of 3 $\mathrm{mg} / 100 \mathrm{~g}$ in the model of HNRP $(\mathrm{n}=10)$.

HNRP simulation was conducted by daily i.p. administration of N-nitro-L-arginine methyl ester (L-NAME) (Sigma, Germany) at a dose of $1.25 \mathrm{mg} / 100 \mathrm{~g}$ of rat mass in a solution form within 28 days and a single increase in intraocular pressure (IOP) to $110 \mathrm{mmHg}$ by applying mechanical pressure to the anterior chamber of the eye for $5 \mathrm{~min}$ on the $26^{\text {th }}$ day of the experiment [26]. The increase in IOP was conducted under general anaesthesia (i.p. chloral hydrate, $30 \mathrm{mg} / 100 \mathrm{~g}$ of rat mass).

For the study, Semax nasal drops, $0.1 \%$ (PEPTOGEN Innovative Research and Production Center) were used. In diseases of the optic nerve, Semax is instilled 2-3 drops in each nasal passage 2-3 times/day. The daily dose is $600-900 \mu \mathrm{g}$. The course of treatment is 7-10 days [32]. 1 drop of the standard solution contains $50 \mu \mathrm{g}$ of the active substance, 0.05 $\mathrm{ml}$ of the solution. The conversion factor for an adult with a body weight of $70 \mathrm{~kg}$ is 39 . For a rat weighing $250 \mathrm{~g}$, the conversion factor is 7.0. Thus, the estimated dose (ED) of Semax was calculated:

$$
\begin{aligned}
\mathrm{ED}_{\mathrm{vol}} & =0.9 \cdot 39 / 70 \cdot 7=0,072 \\
(\mathrm{ml} / \mathrm{kg} / \text { day }) & \\
\mathrm{ED}_{\mathrm{m}} & =0.072 \cdot 50 / 0.05=72 \\
(\mu \mathrm{g} / \mathrm{kg} / \text { day }) & =7.2(\mu \mathrm{g} / 100 \mathrm{~g} / \text { day })
\end{aligned}
$$

A solution of nasal drops was administrated into the nasal cavity using a micropipette once a day daily for 7 days, from the $22^{\text {nd }}$ to the $28^{\text {th }}$ days of the experiment.

The administration of Picamilon (a reference drug) at a dose of $3 \mathrm{mg} / 100 \mathrm{~g}$ (Pharmstandard-UfaVITA JSC, Russia) was conducted 60 minutes before L-NAME administration, from the $22^{\text {nd }}$ to the $28^{\text {th }}$ days of the experiment, inclusive. Picamilon was daily administered intragastrically (i.g.). The choice of Picamilon as a reference drug in the hypertensive neuroretinopathy model, the dose and route of its administration to rats is based on its effectiveness in previously conducted experimental studies at the Research Institute of Pharmacology of Living Systems (BelSU) and published data [26].

The effectiveness of the pharmacological correction with Semax and Picamilon was evaluated on the $29^{\text {th }}$ day of the experiment by the $b / a$ coefficient and retinal microcirculation level.

Laser Doppler Flowmetry. 72 hours after the increase in IOP, the retinal perfusion in rats was measured by LDF. LDF is a noninvasive method for assessing the blood flow in tissues. In LDF, a coherent laser beam illuminates the vascular tissue and measures the Doppler shift caused by the movement of red blood cells. The movement of red blood cells causes a shift in the frequency of scattered light, and the walls of the vessels produce static scattering without any shift in the frequency of light and serve as a reference signal. The registration was performed using MP150 production Biopac System, Inc. (Goleta, USA), a computer-based data acquisition system with the AcqKnowledge 4.2 software, and a TSD-144 needle-type sensor (Biopac System, Inc., Goleta, USA). After the rats were anaesthetized, the retinal perfusion was measured at 10 points on the circumference of the eye [4].

Electroretinography. ERG is the electrical response of the retina to light stimulation. A flash of light causes a two-phase negative-positive waveform. Wave a, which occurs at the photoreceptor level, is the initial large negative wave. The $b$ wave that occurs 
in the inner retina is the next big positive component. The effects of drug therapy can be detected and quantified using ERG [33]. The assessment of retinal functional activity was conducted with a- and b-wave amplitudes. ERG was performed in rats with our previously published method $[2,4]$. The ratio of the amplitudes of the b- and a-waves, the b/a coefficient, was calculated.

Statistical Data Processing. The data were checked for type of distribution. In normal distribution, the average value $(\mathrm{M})$ and standard error of the mean $(\mathrm{m})$ were calculated. In abnormal distribution, the median (Me) and the quartile range (QR) were calculated. Between-group differences were analyzed by parametric (t-Student criterion) or nonparametric (Mann-Whitney U-test) methods. The differences were determined at a 0.05 significance level. The statistical analyses were performed using Statistica 10.0 software.
Results.

$L D F$ results. Results of retinal microcirculation evaluation are presented in Figure 1. In the group with the HNRP simulation, the retinal perfusion decreased by $44.3 \%$ $(\mathrm{p}<0.05)$ in comparison with the control. When correcting HNRP with Semax at a dose of $7.2 \mu \mathrm{g} / 100 \mathrm{~g}$, perfusion level differed significantly (by 9.4\%, p < 0.05) from the mean value of the control group, increased by $62.7 \%$ ( $\mathrm{p}<0.05)$ in comparison with the group with HNRP and differed significantly (by $9.9 \%, p<0.05$ ) from the mean of the group with Picamilon at a dose of $3 \mathrm{mg} / 100 \mathrm{~g}$.

When correcting HNRP with Picamilon, the microcirculation level in the retina differed significantly (by $17.6 \%, \mathrm{p}<0.05$ ) from the mean of the control group, increased by $48.0 \%(\mathrm{p}<0.05)$ in comparison with the group with HNRP simulation.

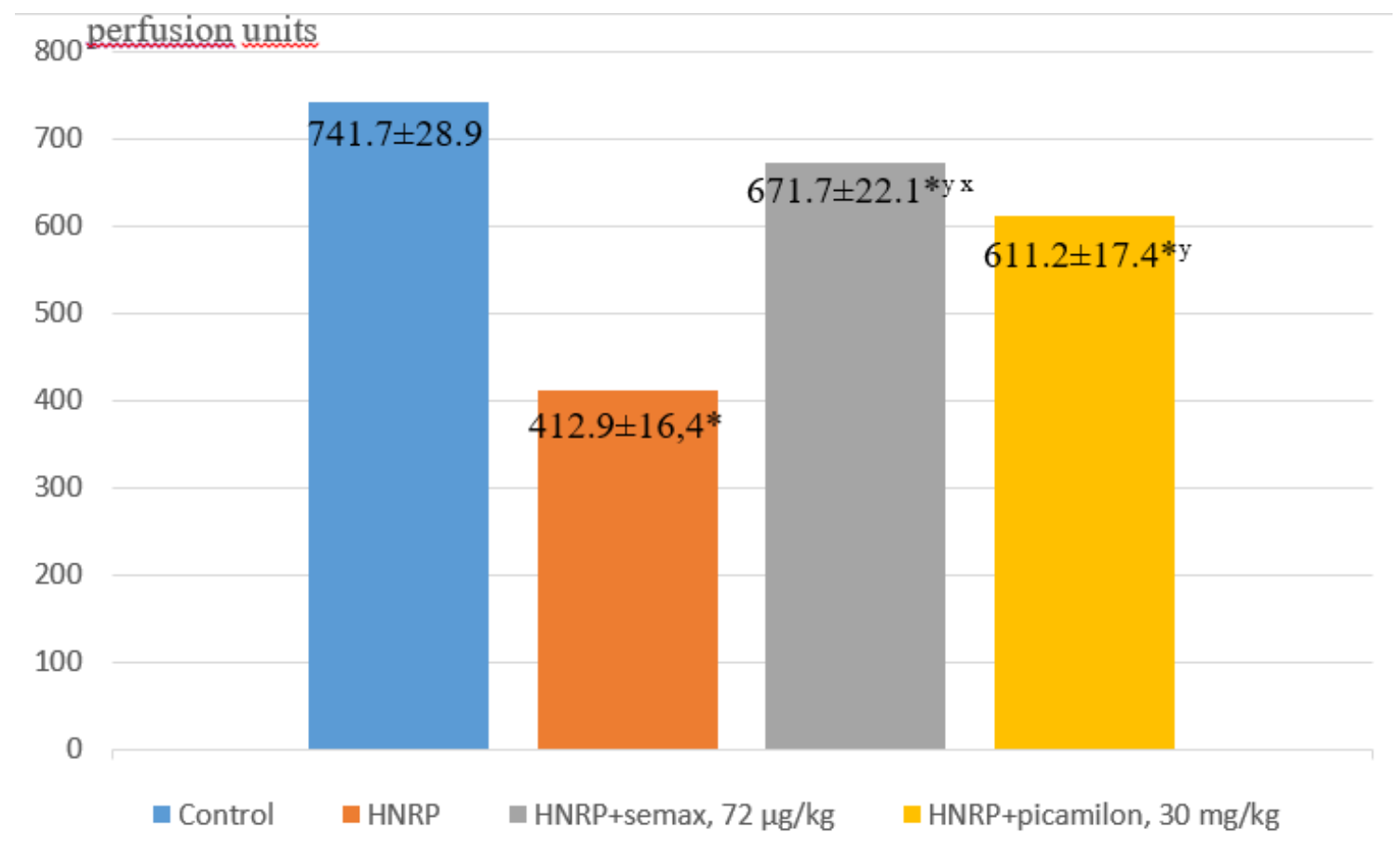

HNRP - hypertensive neuroretinopathy; $* \mathrm{p}<0.05$ compared to the control;

${ }^{\mathrm{y}} \mathrm{p}<0.05$ compared to the group with simulated hypertensive neuroretinopathy;

${ }^{x} \mathrm{p}<0.05$ compared to the group with Picamilon

Fig. 1. Retinal microcirculation level in experimental groups

Results of the ERG, and b/a Counting. The influence of Semax and Picamilon on the values of amplitudes of a- and b-waves in groups is presented in Table 1. Further, the b/a coefficient was calculated, the values of which are presented in Table 2. In the group 
with HNRP simulation, the b/a coefficient decreased by $26.8 \%$ in comparison with the control group $(\mathrm{p}<0.05)$. Against the background of Semax, the b/a coefficient increased by $31.4 \%$ in comparison with the group with no treatment $(\mathrm{p}<0.05)$, and by $14.6 \%$ in com- parison with the group with Picamilon ( $\mathrm{p}<0.05)$. In the group with Picamilon, the b/a coefficient did not reach the target values, but increased by $14.7 \%$ in comparison with the group with no treatment $(\mathrm{p}<0.05)$.

Table 1

Influence of Semax and Picamilon on the a- and b- wave amplitudes when correcting experimental hypertensive neuroretinopathy $(M \pm \mathbf{m} ; \mathbf{n}=10), \mathbf{m V}$

\begin{tabular}{|l|c|c|}
\hline \multicolumn{1}{|c|}{ Experimental Groups } & $\begin{array}{c}\text { The a-Wave Amplitude } \\
(\mathbf{n}=\mathbf{1 0})\end{array}$ & $\begin{array}{c}\text { The b-Wave Amplitude } \\
(\mathbf{n}=\mathbf{1 0})\end{array}$ \\
\hline Control & $0.36 \pm 0.03$ & $0.94 \pm 0.07$ \\
\hline HNRP & $0.34 \pm 0.02$ & $0.65 \pm 0.05^{*}$ \\
\hline HNRP+Semax, $7.2 \mu \mathrm{g} / 100 \mathrm{~g}$ & $0.35 \pm 0.03$ & $0.88 \pm 0.07^{\mathrm{y}}$ \\
\hline HNRP+Picamilon, $3 \mathrm{mg} / 100 \mathrm{~g}$ & $0.36 \pm 0.04$ & $0.79 \pm 0.06^{* \mathrm{y}}$ \\
\hline
\end{tabular}

Note: HNRP - hypertensive neuroretinopathy; ${ }^{*} \mathrm{p}<0.05$ compared to the control; ${ }^{\mathrm{y}} \mathrm{p}<0.05$ compared to the group with simulated HNRP; ${ }^{x} \mathrm{p}<0.05$ compared to the group with Picamilon.

Table 2

\section{Influence of Semax and Picamilon on the value of the b/a coefficient when correcting} experimental hypertensive neuroretinopathy $(M \pm m ; n=10), R . U$.

\begin{tabular}{|l|c|}
\hline \multicolumn{1}{|c|}{ Experimental Groups } & b/a $(\mathbf{n}=\mathbf{1 0})$ \\
\hline Control & $2.61 \pm 0.08$ \\
\hline HNRP & $1.91 \pm 0.06^{*}$ \\
\hline HNRP+Semax, $7.2 \mu \mathrm{g} / 100 \mathrm{~g}$ & $2.51 \pm 0.12^{\mathrm{yx}}$ \\
\hline HNRP+Picamilon, $3 \mathrm{mg} / 100 \mathrm{~g}$ & $2.19 \pm 0.11^{* \mathrm{y}}$ \\
\hline
\end{tabular}

Note: R.U. - relative units; HNRP - hypertensive neuroretinopathy; ${ }^{*} \mathrm{p}<0.05$ compared to the control; ${ }^{\mathrm{y}} \mathrm{p}<0.05$ compared to the group with simulated HNRP; ${ }^{\mathrm{x}} \mathrm{p}<0.05$ compared to the group with Picamilon.

In our opinion, the protective effect of Semax in correction of hypertensive retinal changes in rats may be associated with the presence of neuroprotective, neurometabolic antioxidant and endothelioprotective effects in Semax. Based on the obtained data of the retinal perfusion in the animal groups in the model of hypertensive neuroretinopathy, it follows that a positive effect on the state of the retinal perfusion in descending order has Semax at a dose of $7.2 \mu \mathrm{g} / 100 \mathrm{~g}$, then Picamilon at a dose of $3 \mathrm{mg} / 100 \mathrm{~g}$. Based on the obtained values of the b/a coefficient, it follows that a positive effect on the electrophysiological state of the retina in the correction of hypertensive neuroretinopathy in descending order has Semax at a dose of $7.2 \mu \mathrm{g} / 100 \mathrm{~g}$, then Picamilon at a dose of $3 \mathrm{mg} / 100 \mathrm{~g}$.

It is well known, that the key link in the pathogenesis of endothelial dysfunction is NO deficiency, and the use of drugs that increase NO production has an endothelioprotective effect. Oxidative stress in the retina, which occurs in hypertensive neuroretinopathy, leads to a decrease in NO production, acceleration of its breakdown, and suppression of the expression of endothelial NO synthase (eNOS) [34]. The reasons for the decrease in bioavailability of NO under oxidative stress are an increased level of dimethylarginine formation, which is an endogenous competitive inhibitor of eNOS, as well as a violation of the penetration of L-arginine into endothelial cells under the influence of oxidized lowdensity lipoproteins [35]. In connection with the above, the study of the retinoprotective effect of Semax as a potential corrector of endothelial dysfunction is of particular interest in the model of hypertensive neuroretinopathy.

It is planned to study endothelioprotective effect of Semax at a dose of $7.2 \mu \mathrm{g} / 100 \mathrm{~g}$ of rat mass in the retinal vessels in correction of hypertensive retinal changes in rats using immunohistochemistry, namely the influence on eNOS expression. 
Conclusion. Thus, when correcting HNRP with Semax at a dose of $7.2 \mu \mathrm{g} / 100 \mathrm{~g}$, retinal perfusion increased by $62.7 \%$ (p < 0.05) in comparison with the group with no correction and differed significantly (by 9.9\%, $\mathrm{p}<0.05)$ from the mean value of the group with Picamilon at a dose of $3 \mathrm{mg} / 100 \mathrm{~g}$.

In the group with Semax, the b/a coefficient increased by $31.4 \%$ in comparison with the group with no correction ( $\mathrm{p}<0.05)$, and by $14.6 \%$ in comparison with the group with Picamilon $(p<0.05)$. Therefore, Semax can be a promising agent in the treatment of hypertensive neuroretinopathy.

\section{Financial support}

No financial support has been provided for this work.

\section{Conflict of interests}

The authors have no conflict of interest to declare.

\section{References}

1. Fraser-Bell S, Symes R, Vaze A. Hypertensive eye disease: a review. Clinical and Experimental Ophthalmology. 2017;45(1):45-53. DOI: https://doi.org/10.1111/ceo.12905

2. Akbar S, Akram MU, Sharif M, et al. Arteriovenous ratio and papilledema based hybrid decision support system for detection and grading of hypertensive retinopathy. Computer Methods and Programs in Biomedicine. 2018;154:123-141. DOI: https://doi.org/10.1016/j.cmpb.2017.11.014

3. Stryjewski TP, Papakostas TD, Vavvas D. Proliferative Hypertensive Retinopathy. Journal of the American Medical Association ophthalmology. 2016;134(3):345-346. DOI: https://doi.org/10.1001/jamaophthalmol.2015.558 3

4. Peresypkina A, Pazhinsky A, Danilenko L, et al. Retinoprotective Effect of 2-Ethyl-3hydroxy-6-methylpyridine Nicotinate. Biology (Basel). 2020;9(3):45. DOI: https://doi.org/10.3390/biology9030045

5. Bhargava M, Ikram MK, Wong TY. How does hypertension affect your eyes? Journal of human hypertension. 2012;26(2):71-83. DOI: https://doi.org/10.1038/jhh.2011.37

6. Konstantinidis L. Hypertension and the eye. Current Opinion in Ophthalmology.
2016;27(6):514-521.

DOI: https://doi.org/10.1097/ICU.0000000000000307

7. Kolman SAM, van Sijl AM, van der Sluijs FA, et al. Consideration of hypertensive retinopathy as an important end-organ damage in patients with hypertension. Journal of Human Hypertension. 2017;31(2):121-125. DOI: https://doi.org/10.1038/jhh.2016.49

8. Antsiferov OV, Korokin MV, Gureev $\mathrm{VV}$, et al. Eleven-amino acid peptides that mimic the erythropoietin $\alpha$-helix B increases cell survival in endotheliocyte culture. Archivos Venezolanos de Farmacologia y Terapeutica. 2020;39(5):533537.

DOI: https://doi.org/10.5281/zenodo.4155554

9. Golubev IV, Gureev VV, Korokin MV, et al. Endothelial protective properties of shortchain peptides that mimic $\alpha$-helix b of erythropoietin in experimental preeclampsia. Archivos Venezolanos de Farmacologia y Terapeutica. 2020;39(5):573-577.

DOI: https://doi.org/10.5281/zenodo.4265179

10. Korokin M, Gureev V, Gudyrev O, et al. Erythropoietin Mimetic Peptide (pHBSP) Corrects Endothelial Dysfunction in a Rat Model of Preeclampsia. International Journal of Molecular Sciences. 2020;21(18):6759. DOI: https://doi.org/10.3390/ijms21186759

11.Pokrovskii MV, Soldatov VO, Zatolokina MA, et al. Relation of EPOR/CD131-mediated neuroprotection with modulated gene expression of autophagy, apoptosis, neuroinflammation and neural regeneration in rats under chronic ethanol exposure conditions. Experimental and Clinical Pharmacology. 2021;84(2):91-98. DOI: https://doi.org/10.30906/0869-2092-2021-84-291-98

12. Korokin MV, Soldatov VO, Tietze AA, et al. 11-amino acid peptide imitating the structure of erythropoietin $\alpha$-helix b improves endothelial function, but stimulates thrombosis in rats. Pharmacy \& Pharmacology. 2019;7(6):312-320. DOI: https://doi.org/10.19163/2307-9266-2019-7-6312-320

13. Gusev EI, Martynov MY, Kostenko EV, et al. The efficacy of Semax in the tretament of patients at different stages of ischemic stroke. Zhurnal Nevrologii i Psikhiatrii imeni S.S. Korsakova. 2018;118(3. Vyp. 2):61-68. Russian. DOI: https://doi.org/10.17116/jnevro20181183261-68

14. Medvedeva EV, Dmitrieva VG, Limborska SA, et al. Semax, an analog of ACTH((47)), regulates expression of immune response genes during ischemic brain injury in rats. Molec- 
ular Genetics and Genomics. 2017;292(3):635653. DOI: https://doi.org/10.1007/s00438-017$1297-1$

15. Glazova NY, Manchenko DM, Volodina MA, et al. Semax, synthetic ACTH(4-10) analogue, attenuates behavioural and neurochemical alterations following early-life fluvoxamine exposure in white rats. Neuropeptides. 2020;86:102114. DOI: https://doi.org/10.1016/j.npep.2020.102114

16.Storozhevykh TP, Tukhbatova GR, Senilova YE, et al. Effects of Semax and its ProGly-Pro fragment on calcium homeostasis of neurons and their survival under conditions of glutamate toxicity. Bulletin of Experimental Biology and Medicine. 2007;143(5):601-604. DOI: 10.1007/s10517-007-0192-x

17.Polunin GS, Nurieva SM, Baiandin DL, et al. Evaluation of therapeutic effect of new Russian drug Semax in optic nerve disease. Vestnik Oftalmologii. 2000; 116(1):15-18. Russian.

18.Dolotov OV, Zolotarev IA, Dorokhova EM, et al. The binding of Semax, ACTH 4-10 heptapeptide, to plasma membranes of the rat forebrain basal nuclei and its biodegradation. Russian Journal of Bioorganic Chemistry. 2004;30(3):241-246. Russian. DOI: http://doi.org/10.1023/b:rubi.0000030127.46845.f 0

19. Martynova KV, Andreeva LA, Klimova PA, et al. Structural-functional study of glycineand-proline-containing peptides (glyprolines) as potential neuroprotectors. Russian Journal of Bioorganic Chemistry. 2009;35(2):165-171. DOI: http://doi.org/10.1134/s1068162009020022

20.Stavchansky VV, Yuzhakov VV, Botsina AY, et al. The effect of Semax and its C-end peptide PGP on the morphology and proliferative activity of rat brain cells during experimental ischemia: a pilot study. Journal of Molecular Neuroscience. $\quad 2011 ; 45(2): 177-185$. DOI: http://doi.org/10.1007/s12031-010-9421-2

21.Filippenkov IB, Stavchansky VV, Denisova AE, et al. Novel Insights into the Protective Properties of ACTH(4-7)PGP (Semax) Peptide at the Transcriptome Level Following Cerebral Ischaemia-Reperfusion in Rats. Genes. 2020;11:681.

DOI: https://doi.org/10.3390/genes11060681

22.Tang Y, Le W. Differential roles of M1 and M2 microglia in neurodegenerative diseases. Molecular Neurobiology. 2015;53:1181-1194. DOI: http://doi.org/10.1007/s12035-014-9070-5
23. Shakova FM, Kirova YI, Silachev DN, et al. Protective Effects of PGC-1 $\alpha$ Activators on Ischemic Stroke in a Rat Model of Photochemically Induced Thrombosis. Brain Sciences. 2021;11:325.

DOI: https://doi.org/10.3390/brainsci11030325

24.Elagina AA, Lyashev YuD, Artyushkova $E B$, et al. Peptide preparations protect endothelium against dysfunction caused by diabetes mellitus. Experimental and Clinical Pharmacology. 2020;83(11):12-15. Russian. DOI: http://doi.org/10.30906/0869-2092-2020-83-11$12-15$

25.Elagina AA, Lyashev YuD, Artyushkova EB, et al. Antioxidant effect of peptide drugs in diabetes mellitus. Vestnik NovSU. 2020;4(120):70-74. Russian. DOI: https://doi.org/10.34680/20768052.2020.4(120).70-74.

26. Gubareva VO, Pazhinsky AL, Zhernakova NI, et al. Protective effects of 11-amino acid darbepoetin fragment in the experimental hypertensive neuroretinopathy. Drug Invention Today. 2019;12(11):2726-2730.

27. Alrashdi SF, Deliyanti D, WilkinsonBerka JL. Intravitreal administration of endothelin type A receptor or endothelin type B receptor antagonists attenuates hypertensive and diabetic retinopathy in rats. Experimental Eye Research. 2018;176:1-9.

DOI: https://doi.org/10.1016/j.exer.2018.06.025

28. Reichhart N, Haase N, Crespo-Garcia S, et al. Hypertensive retinopathy in a transgenic angiotensin-based model. Clinical Science. 2016;130(13):1075-1088. DOI: https://doi.org/10.1042/CS20160092

29.Li Y, Wang Q, Muir ER, et al. Retinal Vascular and Anatomical Features in the Spontaneously Hypertensive Rat. Current Eye Research. 2020;45(11): 1422-1429.

DOI: https://doi.org/10.1080/02713683.2020.1752738

30. McDonald L, Lee GR, Degooyer TE, et al. Effects of an endothelin receptor antagonist on a model of hypertensive retinopathy. Ophthalmic Research. 2010;43(2):99-107. DOI: https://doi.org/10.1159/000247594

31.Peresypkina AA, Pazhinsky AL, Pobeda AS, et al. The development of hypertensive neuroretinopathy model. Indo American journal of pharmaceutical sciences. 2017;4(10):3695-3700. DOI: http://doi.org/10.5281/zenodo.1019417 
32.Vidal [Internet]. [cited 2021 March 19]. Available from:

https://www.vidal.ru/drugs/Semax_28676

33. Creel DJ. Electroretinograms. Handbook of Clinical Neurology. 2019;160:481-493. DOI: http://doi.org/10.1016/B978-0-444-640321.00032-1

34.Peresypkina AA, Pokrovskii MV, Gubareva VO, et al. Protective effect of carbamylated darbepoetin on the model of ischemic neuropathy of the optic nerve in rats. Experimental and Clinical Pharmacology. 2018;81:8-13. Russian. DOI: http://doi.org/10.30906/0869-2092-2018-81-7-813

35.Cooke JP. Asymmetrical dimethylarginine: the Uber marker? Circulation. 2004;109(7):1813-1818. DOI: 10.1161/01.CIR.0000126823.07732.D5

Received 24 March 2021

Revised 22 May 2021

Accepted 4 June 2021

\section{Information about the authors}

Sergey S. Lugovskoy, Post-graduate Student in scientific specialty 14.03.06 - Pharmacology, Clinical Pharmacology, Belgorod State National Research University, Belgorod, Russia, E-mail: lug90@mail.ru, ORCID: https://orcid.org/00000002-5726-220X.

Sofia S. Chernyaeva, Post-graduate Student in scientific specialty 14.03.06 - Pharmacology, Clinical Pharmacology, Belgorod State National
Research University, Belgorod, Russia, E-mail: sonyachernyaeva@yandex.ru, ORCID: https://orcid.org/0000-0002-3937-2472.

Anna A. Peresypkina, Doct. Sci. (Biology), Professor at the Department of Pharmacology and Clinical Pharmacology, Belgorod State National Research University, Belgorod, Russia, E-mail: peresypkina_a@bsu.edu.ru, ORCID: https://orcid.org/0000-0003-2829-9860.

Anna S. Pobeda, Cand. Sci. (Biology), Associate Professor at the Department of Pharmacology and Clinical Pharmacology, Belgorod State National Research University, Belgorod, Russia, E-mail: pobeda@bsu.edu.ru,

ORCID: https://orcid.org/0000-0002-0541-8946.

Nikolai V. Solovev, Ophthalmologist at the Consultative and Polyclinic Department, Ophthalmological Clinical Hospital - Ophthalmological Center, Kursk, Russia, E-mail: morkovkapro@mail.ru, ORCID: https://orcid.org/00000002-3824-9181.

Kristina V. Shchurovskaya, Post-graduate Student in scientific specialty 14.03.06 - Pharmacology, Clinical Pharmacology, Belgorod State National Research University, Belgorod, Russia, E-mail: kristinka-i@yandex.ru, ORCID: https://orcid.org/0000-0001-8205-750X.

Igor N. Iezhitsa, Dr Sci Biol, PhD, Professor at the Department of Pharmacology \& Therapeutics, School of Medicine of the International Medical University, Kuala Lumpur, Federal Territory of Kuala Lumpur, Malaysia, E-mail: iezhitsa@yandex.ru, ORCID: https://orcid.org/00000002-2852-8486. 